\section{Isolation of a New Indole Alkaloid, Roquefortine D, from the Cultures of Penicillium roqueforti}

\author{
Sadahiro Oнмомо, Kiyoshi Oguma,* \\ Tsutomu ŌHASHI and \\ Matazo ABE**
}

Institute of Applied Biochemistry, The University of Tsukuba, Ibaraki-ken 300-31 * Faculty of Agriculture, Tokyo University of Education, Komaba, Meguro-ku, Tokyo 153

**Faculty of Agriculture, Tamagawa University, Machida-shi, Tokyo 194

Received May 15, 1978

Previously, we $\mathrm{e}^{1-3)}$ isolated three indole alkaloids, roquefortine $\mathrm{A}, \mathrm{B}$ and $\mathrm{C}$, from the cultures of Penicillium roqueforti, and made clear the structures of those alkaloids. Recently, we have isolated the unknown indole alkaloid " $Z$," which was found in the course of previous experiment, ${ }^{3)}$ from the cultures of the same Penicillium mold. This alkaloid " $Z$ " was obtained in the yields of $50 \mathrm{mg}$ together with $600 \mathrm{mg}$ of roquefortine $\mathrm{C}$ from the mycelium and the culture filtrate, when a selected strain was grown at $30^{\circ} \mathrm{C}$ for 20 days in 100 Roux flasks ( 1 liter capacity), containing each $200 \mathrm{ml}$ of the mannitol-glucose-ammonium succinatemedium.

The alkaloid " $\mathrm{Z}$ " crystallized from acetonitrile or methanol in colorless prisms; $\mathrm{mp} 153 \sim 154^{\circ} \mathrm{C},[\alpha]_{\mathrm{D}}^{15}-$ $370^{\circ} \quad(c=0.23$, pyr.). The molecular formula was $\mathrm{C}_{22} \mathrm{H}_{25} \mathrm{~N}_{3} \mathrm{O}_{2}$. Its IR-spectrum contained bands assignable to a diketopiperazine unit, ${ }^{4)}$ strong absorption at 3200 and $1660 \mathrm{~cm}^{-1}$ and absence of the amide II band in the region of $1515 \sim 1570 \mathrm{~cm}^{-1}$ (Fig. 1). Its NMR-spectrum possessed no singlet assignable to a vinyl proton of dehydrohistidine side chain of roquefortine $\mathrm{C}$ and had three double doublet at $\delta 2.88, \delta 3.32$ and $\delta 4.08$, which are absent in the spectrum ${ }^{3\rangle}$ of roquefortine C. The other signals of " $Z$ " were all similar to those of roquefortine $C$. These data suggested that

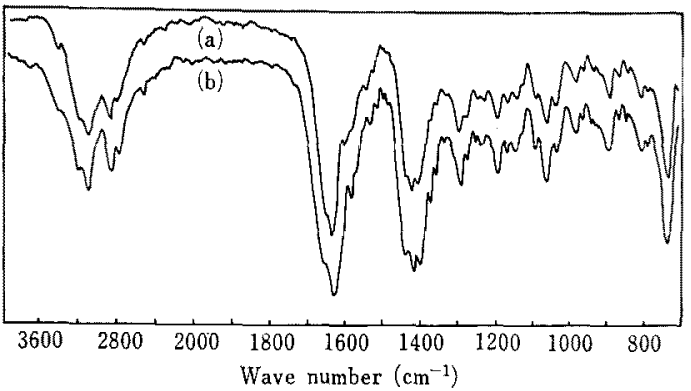

FIG. 1. IR-spectra of Alkaloid " $Z$ " (Roquefortine D) (a) and Isomer-1 of Dihydroroquefortine C (b) in $\mathrm{KBr}$.

alkaloid " $Z$ " might be a dihydro-derivative of roquefortine $\mathrm{C}$ in the part of dehydrohistidine side chain. This was suported strongly by the MS-spectrum. Namely, the primary fragmentation of " $Z$ " was the loss of a $\mathrm{C}_{5} \mathrm{H}_{8}$ radical (mass 69 ) to give a prominent fragment (fragment $\mathrm{A}$ shown here) at $m / e 322$ (base peak). And fragment $\mathbf{B}(m / e 194), C(m / e ~ 130)$ and $D$

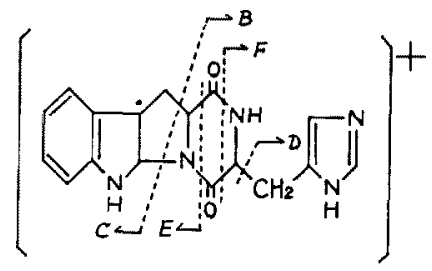

Fragment A

$(m / e 81)$, each originated from cleavage in the expected position $\alpha$ to the diketopiperazine ring of fragment $A$, appeared. Fragment E (m/e 157) and F (m/e 110), originated from cleavage of the diketopiperazine ring ${ }^{57}$ of fragment A, also appeared. Comparing these fragments with those ${ }^{3)}$ of roquefortine $\mathrm{C}$, fragment $\mathrm{A}, \mathrm{B}$ and $\mathrm{F}$ were two mass units larger than those $(\mathrm{m} / \mathrm{e} 320$, 192 and 108) of roquefortine $C$, respectively. Also, fragment $D$ is an unique fragment which can not appear in the spectrum of roquefortine $C$ owing to the conjugated double bond.

Reduction of roquefortine $\mathrm{C}$ [I] with $\mathrm{Zn}$ in acetic acid caused hydrogenation in the part of dehydrohistidine side chain and afforded mixtures of two stereoisomers (isomer-1 and -2) of dihydroroquefortine $\mathrm{C}$

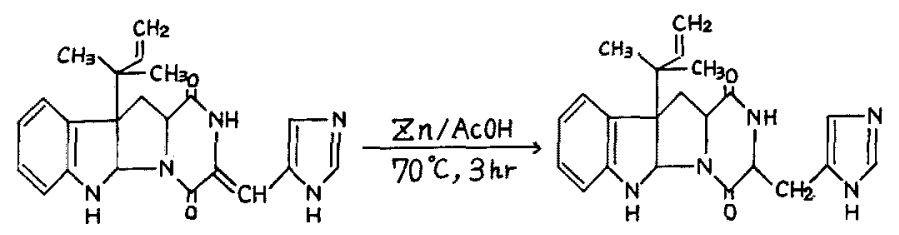


[II]. The isomer-1 crystallized from methanol in colorless prisms; mp $154^{\circ} \mathrm{C},[\alpha]_{\mathrm{D}}^{1 \mathrm{~b}}-372^{\circ}(c=0.3$, pyr.). The isomer-2 showed such physico-chemical properties as mentioned later.

The chemical and spectro-chemical properties of the alkaloid " $Z$ " were all found to be identical with those of an isomer (isomer-1) of dihydroroquefortine $\mathrm{C}$ mentioned here. The thin-layer chromatographic behaviours of " $Z$ " in different systems ${ }^{b \text { ) }}$ were also corresponded well with those of the isomer-1 of dihydroroquefortine C. Finally, " $Z$ " was found to be just identical with the isomer-1 of dihydroroquefortine $C$ from the mixed melting point.

From these facts, the alkaloid " $Z$ " was a new indole alkaloid having the structure [II], for which we propose the name roquefortine $D$.

By the way, the said isomer- 2 of dihydroroquefortine $\mathrm{C}$ (stereoisomer of roquefortine $\mathrm{D}$ ) could not be found in the cultures of the tested Penicillium strain.

\section{EXPERIMENTAL}

Fungus and cultivation. A strain of Penicillium roqueforti, which was selected in the previous experiments, ${ }^{1-3)}$ was cultivated at $30^{\circ} \mathrm{C}$ for 20 days in 100 of 1 liter Roux flasks, containing each $200 \mathrm{ml}$ of the medium composed of mannitol $30 \mathrm{~g}$, glucose $10 \mathrm{~g}$, succinic acid $10 \mathrm{~g}, \mathrm{KH}_{2} \mathrm{PO}_{4} 1 \mathrm{~g}, \mathrm{MgSO}_{4} \cdot 7 \mathrm{H}_{2} \mathrm{O} 0.3 \mathrm{~g}$, $\mathrm{NH}_{4} \mathrm{OH}$ (to $\mathrm{pH} 5.6$ ) and tap water (1 liter).

Isolation of alkaloid " $Z$ " (Roquefortine $D$ ). The alkaloids were extracted from the cultures with ethyl acetate in the presence of ammonia ( $\mathrm{pH}$ ca. 10). The alkaloidal extract was dissolved in $3 \%$ aqueous solution of tartaric acid and reextracted with chloroform in the presence of ammonia. The alkaloidal solution thus obtained was concentrated to dryness and the residue was passed through a column $(3.5 \times 40 \mathrm{~cm})$ containing $280 \mathrm{~g}$ of alumina (WAKO, activity II) suspended in chloroform. The column was first eluted with $600 \mathrm{ml}$ of chloroform containing $1 \%$ ethanol (v/v) and next eluted with $1200 \mathrm{ml}$ of chloroform containing $5 \%$ ethanol $(\mathrm{v} / \mathrm{v})$ at a rate of $20 \mathrm{~g} /$ tube $/ 20 \mathrm{~min}$. Alkaloid " $Z$ " was contained in fractions No. $71 \sim 97$ together with roquefortine $C$. These fractions were combined and evaporated to dryness under reduced pressure. The residue was next passed through a column $(1.8 \times 80 \mathrm{~cm})$ containing $120 \mathrm{~g}$ of silica gel (WAKO, WAKOGEL Q-23) suspended in ammoniacal chloroform. The column was in turn eluted with i) $500 \mathrm{ml}$ of ammoniacal chloroform* containing $3 \%$ methanol $(\mathrm{v} / \mathrm{v})$, ii) $700 \mathrm{ml}$ of ammoniacal chloroform* containing $5 \%$ methanol $(\mathrm{v} / \mathrm{v})$ and, iii) $800 \mathrm{ml}$ of ammoniacal chloroform* containing $7 \%$ methanol $(\mathrm{v} / \mathrm{v})$

* Mixture of 10 parts of chloroform and 1 part of chloroform saturated with conc. anmonia. at a rate of $20 \mathrm{~g} / \mathrm{tube} / 30 \mathrm{~min}$. Alkaloid " $\mathrm{Z}$ " was contained in fractions No. $63 \sim 98$. These fractions were combined and evaporated to dryness under reduced pressure. The residue gave crystalls of " $Z$ " from its benzene-acetonitrile solution ( $50 \mathrm{mg}$ ). " $Z$ " was crystallized from acetonitrile in colorless prisms; mp $153 \sim$ $154^{\circ} \mathrm{C},[\alpha]_{\mathrm{D}}^{15}-370^{\circ}(c=0.23$, pyr.), molecular formula $\mathrm{C}_{22} \mathrm{H}_{25} \mathrm{~N}_{5} \mathrm{O}_{2}$ [Found: $\mathrm{C}, 67.62 ; \mathrm{H}, 7.20 ; \mathrm{N}, 16.92 ; \mathrm{m} / \mathrm{e}$, $391\left(\mathrm{M}^{+}\right)$. Calcd. for $\mathrm{C}_{22} \mathrm{H}_{25} \mathrm{~N}_{5} \mathrm{O}_{2}: \mathrm{C}, 67.50 ; \mathrm{H}, 6.69$; $\mathrm{N}, 17.89 \%$; MW, 391.46]. Color reactions: modified Ehrlich's reagent $t^{B}$ (yellow green, turning gradually into purplish blue), Pauly reagent ${ }^{7}$ (reddish orange), Dragendorff reagent (orange), $2 \% \mathrm{KMnO}_{4}$ reagent (positive), $5 \% \mathrm{FeCl}_{3}$ reagent (negative). $\mathrm{UV} \lambda_{\max }^{\mathrm{EtOH}} \mathrm{nm}$ $(\log \varepsilon): 208$ (5.29), 244 (4.55), 298 (4.18). IR $\nu_{\max }^{\mathrm{KBr}}$ $\mathrm{cm}^{-1}: 3200(\mathrm{NH}), 1660$ (amide I), 1440, 1085, 750 (Fig. 1). MS m/e: $391\left(\mathrm{M}^{+}\right), 322\left(\mathrm{M}^{+}-\mathrm{C}_{5} \mathrm{H}_{2}, 100 \%\right)$, 294, 241, 198, $194(14 \%), 185,157(16 \%), 130(52 \%)$, $110(78 \%), 81(23 \%), 69(49 \%), 28$. NMR $\delta_{\mathrm{TMS}}^{\mathrm{CDCl}_{3}}$ : $0.98\left(3 \mathrm{H}, \mathrm{s}, \mathrm{CH}_{3}-\mathrm{I}_{\mathrm{l}}-\right), 1.09\left(3 \mathrm{H}, \mathrm{s}, \mathrm{CH}_{3}-\stackrel{+}{\mathrm{C}}-\right), 2.26 \sim 2.54$ $(2 \mathrm{H}, \mathrm{m}), 2.88(1 \mathrm{H}, \mathrm{dd}, J=9$ and $17.5 \mathrm{~Hz}), 3.32(1 \mathrm{H}, \mathrm{dd}$, $J=5$ and $17.5 \mathrm{~Hz}), 3.86(1 \mathrm{H}, \mathrm{m}), 4.08(1 \mathrm{H}, \mathrm{dd}, J=5$ and $9 \mathrm{~Hz}), 4.85 \sim 5.10(2 \mathrm{H}, \mathrm{m}), 5.46(1 \mathrm{H}, \mathrm{s}), 5.7 \sim 6.1$ $(1 \mathrm{H}, \mathrm{m}), 6.5 \sim 7.25(4 \mathrm{H}, \mathrm{m}$, indole protons), $6.98(1 \mathrm{H}$, $\mathrm{s}$, imidazole $-\stackrel{\mathrm{C}}{\mathrm{C}}=\mathrm{CH}-), 7.43(1 \mathrm{H}, \mathrm{s}$, imidazole $-\mathrm{C}=\mathrm{CH}-)$, 7.52 ( $1 \mathrm{H}$, br. $\mathrm{s},-\mathrm{NH}-$, disappeared on $\mathrm{D}_{2} \mathrm{O}$ exchange), From the fractions No. $30 \sim 52$ in the above column chromatography, roquefortine $\mathrm{C}$ was obtained in the yields of $600 \mathrm{mg}$.

Preparation of dihydroroquefortine $C$. Zine powder $(2 \mathrm{~g})$ was added to a solution of roquefortine $\mathrm{C}(200 \mathrm{mg})$ in acetic acid $(10 \mathrm{ml})$. After refiux for $3 \mathrm{hr}$ at $70^{\circ} \mathrm{C}$, 10-fold by volume of $\mathrm{H}_{2} \mathrm{O}$ was added into reaction mixture, and then alkaloids were extracted with ethyl acetate at $\mathrm{pH} 10(\mathrm{NaOH})$. Alkaloidal extract was purified by column chromatography on silica gel mentioned before. From the eluted fractions No. 60 93, $52 \mathrm{mg}$ of one stereoisomer (isomer-1) of dihydroroquefortine $\mathrm{C}$ was obtained in crystalline powder (yield $26 \%) ; \operatorname{mp~} 154^{\circ} \mathrm{C},[\alpha]_{\mathrm{D}}^{15}-372^{\circ}(c=0.3$, pyr), molecular formula $\mathrm{C}_{22} \mathrm{H}_{25} \mathrm{~N}_{5} \mathrm{O}_{2}$ [Found: $\mathrm{C}, 67.47 ; \mathrm{H}$, $\left.6.74 ; \mathrm{N}, 17.78 \% ; m / e 391\left(\mathrm{M}^{+}\right)\right]$. UV $\lambda_{\max }^{\mathrm{EtOH}} \mathrm{nm}$ $(\log \varepsilon): 208$ (5.28), 244 (4.55), 298 (4.18). IR $\nu_{\mathrm{max}}^{\mathrm{KBF}}$ $\mathrm{cm}^{-1}: 1660$ (amide I) (Fig. 1). MS m/e: $391\left(\mathrm{M}^{+}\right)$, $322,294,241,194,185,157,130,110,81,69,28$. From the fractions No. $104 \sim 140$ in the same column chromatography, $50 \mathrm{mg}$ of another stereoisomer (isomer-2) of dihydroroquefortine $\mathrm{C}$ was obtained in crystalline powder (yield $25 \%$ ): mp $185^{\circ} \mathrm{C},[\alpha]_{\mathrm{D}}^{15}-137^{\circ}(c=0.33$, pyr.), IR $\nu_{\mathrm{max}}^{\mathrm{KBr}} \mathrm{cm}^{-1}: 1665$ (amide $\mathrm{D}, \mathrm{MS} \mathrm{m} / \mathrm{e}: 391$ $\left(\mathrm{M}^{+}\right), 322,294,241,194,185,157,130,110,81,69,28$.

Acknowledgment. We wish to express our sincere 
thanks to Dr. H. Inoue and Dr. T. Asao, Proffessors of Tōhoku University, for their kind co-operation in elemental analysis and NMR- and MS-spectrum measurements.

\section{REFERENCES}

1) S. Ohmomo, T. Sato, T. Utagawa and M. Abe, Agric. Biol. Chem., 39, 1333 (1975).

2) S. Ohmomo, T. Sato, T. Utagawa and M. Abe,
Nippon Nôgeikagaku Kaishi, 49, 615 (1975).

3) S. Ohmomo, T. Utagawa and M. Abe, Agric. Biol. Chem., 41, 2097 (1977).

4) P. S. Steyn, Tetrahedron Lett., 1971, 3331.

5) H. J. Svec and G. A. Junk, J. Am. Chem. Soc., 86, 2278 (1964).

6) S. Ohmomo and M. Abe, Nippon Nôgeikagaku Kaishi, 50, 331 (1976).

7) T. Mann and E. Leone, Biochem. J., 53, 140 (1953). 